\title{
REBELIONES QUITEÑAS PERSISTENCIA Y TRANSFORMACIONES DE LA PROTESTA
}

\author{
René Unda Lara**
}

\section{Introducción: quiteñidad de/en las rebeliones quiteñas}

Hablar de rebeliones quiteñas, más allá de su intrínseca complejidad, plantea una dificultad inicial que es necesario despejar desde el inicio de este trabajo y es la referida a los probables equívocos de interpretación sobre un supuesto carácter "quiteñocéntrico" de la protesta. De hecho, las rebeliones quiteñas podrán ser comprendidas mejor siempre que el análisis trascienda el limitado marco geográfico de la quiteñidad, entendida como el espacio físico de la ciudad de Quito y los habitantes nacidos en Quito.

Evidentemente, una concepción de tal naturaleza, además de restringida resulta irreal. Primero, porque significaría desechar groseramente del análisis el proceso de configuración y composición sociourbana de Quito, en el

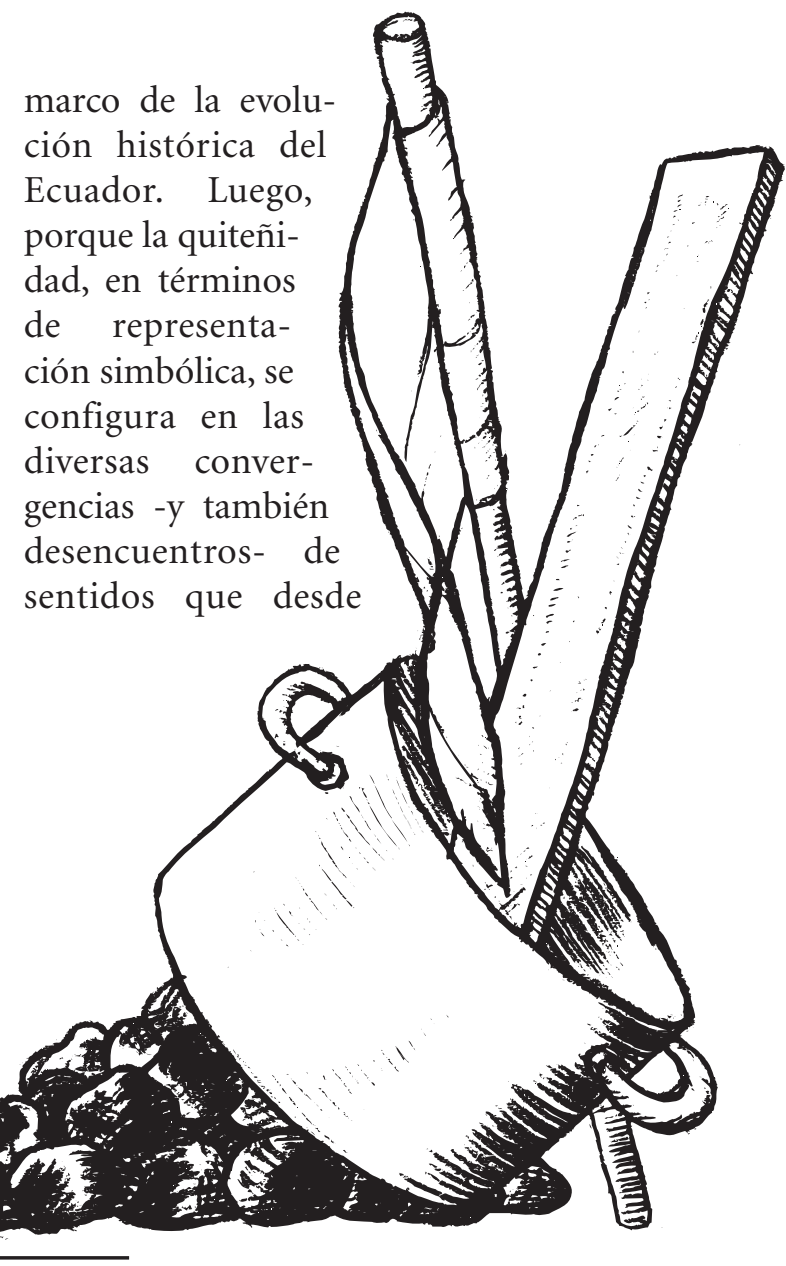

marco de la evolu-
ción histórica del Ecuador. Luego, porque la quiteñidad, en términos de representación simbólica, se configura en las diversas convergencias -y también desencuentros- de sentidos que desde

* Versión actualizada de la ponencia presentada en el Foro "Prohibido Olvidar" (septiembre 2005) organizado por el Consejo Metropolitano del I. Municipio de Quito a propósito de los sucesos de abril de 2005 en Quito. Para su publicación en otros medios, se cuenta con la autorización del editor de las memorias de este evento.

* René Unda Lara, Director de la Maestría en Políticas para la Infancia y la Adolescencia de la Universidad Politécnica Salesiana-Ecuador. 
distintas procedencias geográficas y culturales la constituyen.

Esta consideración inicial evitaría interpretaciones que, en un malentendido regionalismo, se conviertan en instrumento de dudosos usos políticos. Las rebeliones quiteñas, en suma, condensan geografías físicas y simbólicas de diversa procedencia e, incluso, no sólo enmarcadas en lo nacional o en lo estrictamente político ${ }^{1}$. Creemos que esa argamasa de sentidos constituye el sustrato básico de las rebeliones quiteñas que, como se explicará más adelante, por efectos de una concentración de factores de distinta índole, la han dotado de una particular especificidad que refuerza el imaginario político de Quito "Luz de América" y de epicentro de la política nacional.

En el plano de la evidencia empírica, las constataciones no dejan lugar a dudas; quienes han participado y participan en las diversas líneas de contestación o de reactividad frente a los múltiples efectos de la aplicación de políticas de corte neoliberal no necesariamente son nacidos en Quito y, en varias revueltas importantes, se ha constatado también que los actores protagónicos tampoco residen en la capital.

Por lo tanto, las rebeliones quiteñas suponen una apropiación simbólica -individual y colectiva- del sentido histórico con el que Quito se ha construido como capital política del Ecuador. Estar en Quito confiere, en gran medida, la probabilidad de ser parte de acciones sociopolíticas o abiertamente políticas en las que, generalmente, es el sistema político o alguno de sus componentes el objeto del descontento popular y, por otro lado, permite evidenciar la capacidad erosionada, aún vigente del Estado, como productor de sociedad ${ }^{2}$. Lo que, dicho de otra manera, significa que las acciones u omisiones del Estado, en tanto sistema político, generan e instalan en el Quito territorial un muy sensible escenario de confrontación que al tomar la forma de protesta produce, efectos diferenciados respecto de otros puntos geográficos del Ecuador.

Existe, un conjunto de condiciones que hacen de Quito y sus rebeliones un "producto" particular. Como

1 Tanto la historia de las luchas independentistas de la corona española con notoria influencia de actores de procedencia extranjera, así como las recientes apropiaciones de discursividades (consignas, proclamas, cánticos, gestualidades) de distinto orden y procedencias muestran un cierto carácter cosmopolita del que se han nutrido las rebeliones quiteñas.

2 Cfr. Alain Touraine, Actores Sociales y Sistemas Políticos en América Latina, PREALC, Santiago, 1987. Véase también Simón Pachano, "Los que sobran en el escenario vacio", en Ecuador Debate n. 19, Políticas Sociales, diciembre, 1989. 
se ha señalado ya, su misma historia política, rica en pluralidades intra y extra nacionales, así como su condición de centro de la gestión política estatal del Ecuador, a lo que cabría agregar los efectos del proceso de modernización socioeconómica, impulsado, desde la década del setenta, con las exportaciones petroleras, son hechos que, definitivamente, afirman tal particularidad en el marco de un esquema bipolar (Quito, Guayaquil) del modelo de desarrollo y concentración urbana, económica y política del Ecuador.

En este modelo bipolar de desarrollo nacional, en el que Quito representa el epicentro de la política nacional y, Guayaquil el polo de desarrollo económico y comercial, se construyen representaciones e imaginarios endógenos que vinculan el ser quiteño con la proximidad a la institucionalidad política en cualquiera de sus formas. Y, representaciones e imaginarios políticos exógenos que se construyen desde las provincias en las que la más o menos forzada proyección latente de "vivir en Quito" significa también la posibilidad de ser parte, por diversas vías, de la acción colectiva y política nacional.

Por una parte, es la misma cercanía -relativa desde luego- del habitante común de Quito con las instituciones políticas la que genera posibilidades de contestación y reactivi- dad y, por otro lado, también la relativa proximidad entre Quito y el resto de las provincias del Ecuador la que alimenta dichas posibilidades, cuestión bastante diferenciada si se la compara, por ejemplo, con el caso de los países de la región andina.

\section{Las rebeliones quiteñas suponen una apropiación simbólica -individual y colectiva- del sentido histórico con el que Quito se ha construido como capital política del Ecuador.}

La extensión territorial del Ecuador, pequeña con relación a los países de la región andina, así como la marcada bipolaridad de su desarrollo nacional, serían factores relevantes a considerar en el análisis del carácter de las protestas, sus actores y eficacias. Y, en gran medida, es lo que permitiría comprender el carácter de las llamadas insubordinaciones quiteñas como dimensión crucial de la identidad quiteña.

Esta preliminar aproximación en torno al carácter de las rebeliones quiteñas merece, con toda seguridad, indagaciones más profundas y espe- 
cíficas ya que es la misma identidad quiteña, en toda su complejidad, la que se construye y afirma con las revueltas que en Quito se producen.

Bajo estas consideraciones iniciales, el presente análisis sobre las rebeliones quiteñas centra su interés analítico e interpretativo en varios de los aspectos que configuran sus rupturas $\mathrm{y}$ continuidades en las distintas fases de la protesta que, como expresión del conflicto sociopolítico, han tenido lugar en Quito, considerando algunas de sus memorias más relevantes como la "Guerra de los Cuatro Reales" en abril de 1978, la "Revuelta Forajida" en abril de 2005, y las más recientes protestas dirigidas ya no contra el gobierno y el Presidente de turno, sino contra el congreso y, sobre todo, contra los diputados.

Para tal efecto se realiza: a) una aproximación conceptual sobre el carácter y transformaciones de la protesta a partir de 1978, ubicando como marco empírico de referencia algunas de las rebeliones quiteñas más significativas en términos de expresión del conflicto social y político; b) un recorrido analítico de la protesta, por décadas, en el que la explicación privilegia el marco general de condiciones políticas y económicas, cuyos efectos confirman la persistencia variable de la protesta frente a la inconsistencia creciente de la acción gubernativa y del sistema de repre- sentación política; c) un conjunto de planteamientos preliminares sobre la creciente y decisiva presencia de los sectores medios quiteños en las protestas de rebelión y que, finalmente, delinea hipótesis explicativas sobre la emergencia y carácter actual de este fenómeno.

\section{La persistencia de la protesta en el sistema social y en el sistema político ecuatoriano}

Se asume, con la clara intención de ampliar un debate teórico, que la protesta, en el caso ecuatoriano, se enmarca en las transformaciones del conflicto social y del conflicto político y que, por la particular configuración del sistema político y de la sociedad ecuatoriana, no llega a constituirse como una expresión social y política relativamente autónoma del conflicto.

En suma, la protesta sería una de las expresiones persistentes de un conflicto social desinstitucionalizado, al desbordar las reglas establecidas y aceptadas por los actores en conflicto. Esta observación podría extenderse al conflicto político con el agravante de que la conflictividad social, expresada bajo la forma de protesta, tiende a procesarse de modo directo en la esfera gubernamental y en la figura presidencial sin que exista necesariamente la mediación e in- 
tervención de las instancias y actores del sistema político en su conjunto ${ }^{3}$.

Y, ello, debido a factores de orden histórico-estructural relacionados con el alto nivel de opacidad institucional del sistema político ecuatoriano en su conjunto, expresado tanto en la estructura, cuanto en las funciones del sistema de gobierno, del sistema de representación y de la administración pública; a lo que debe agregarse, desde un marco temporal más reciente, factores atribuibles a los avatares de una inducida modernización socioeconómica $\left(70^{\prime}\right)$ y los efectos sucesivos tanto de las políticas de ajuste estructural (80') como de la implantación de las políticas neoliberales de alcance global (90').

En tal medida, creemos que en el caso ecuatoriano y con mayor énfasis a partir de los años setenta, siempre resultó bastante difícil distinguir con claridad los límites entre el conflicto social, tal como prescribe bajo diversos enfoques la democracia moderna (demandas y reivindicaciones sociales) y el procesamiento político del conflicto (acumulación y toma del poder, consensos políticos, consistencia del régimen político y gubernamental). Por esta razón, la protesta, creemos, siempre estuvo altamente politizada y privilegió su acción política hacia el enfrentamiento directo con el poder ejecutivo $y$, más específicamente, con el Presidente de turno. No es sino hasta luego del derrocamiento de Lucio Gutiérrez que las expresiones generalizadas de repudio latente hacia el Congreso y los congresistas se vuelven manifiestas y alcanzan intensidades inéditas en el país.

$\mathrm{Al}$ respecto, las mediaciones sociales y las mediaciones políticas institucionales que la democracia prevé para el procesamiento del conflicto han sido, por decir lo menos, ineficientes, aunque sobre uno y otro ámbito pesen distintas presiones y responsabilidades y desarrollen acciones bajo condiciones, en mayor o menor grado, diferenciadas.

Las diversas agregaciones societales, por la misma constitución histórica del Estado desarrollado a "espaldas de la sociedad" 4 , difícilmente han

Cfr. Norberto Bobbio, et. al. , Diccionario de Política, siglo XXI, México, 2000. Véase también J. Sánchez-Parga, Del conflicto social al ciclo político de la protesta, en Ecuador Debate n. 64, abril 2005; allí se explica que son las causas, procesamiento y efectos los que determinan el carácter del conflicto y se trabaja la hipótesis de que el conflicto social en el Ecuador ha dejado de ser tal para dar paso al ciclo político de la protesta (subrayado nuestro). 
interlocutado institucional y formalmente con las instancias y dispositivos del sistema político para el procesamiento de sus demandas, hecho que ha orientado las acciones de protesta y contestación por derroteros distintos a los que se esperaría en el marco del funcionamiento democrático con lo cual las protestas, por lo general, han identificado al gobierno como el "enemigo" a derrotar'. Esto, hasta el derrocamiento de Gutiérrez.

En este sentido, cabe resaltar la decisiva presencia en el imaginario social y político de la figura presidencial y del modelo presidencialista, con todas las connotaciones de patrimonialismo y caciquismo, posiblemente heredadas de la época de la colonia, que la sociedad ecuatoriana ha internalizado y expresa con distinto grado de intensidad en las movilizaciones de protesta.

Sin embargo, con la llegada al poder gubernamental de Rafael Correa, la protesta popular enfila sus consignas y sus acciones contra los diputados más que contra la institución y poder legislativo, puesto que se encuentra en ciernes la inminente realización de la Asamblea Constituyente, factor decisivo en la candidatura electoral y posterior triunfo de Correa en las últimas elecciones presidenciales.

Aunque el análisis de recomposición y reestructuración de fuerzas al interior del sistema político amerita otro espacio de análisis, en la perspectiva de estudio sobre la protesta, debe decirse que es el mismo sistema político el que sigue cuestionado; el hecho de que el presidente Correa disponga de un enorme y masivo apoyo popular no significa necesariamente que la sociedad haya encontrado vías adecuadas y satisfactorias para resolver el problema de la representación política. Es cabalmente, el mecanismo de la Constituyente la apuesta sobre la que se ciernen las posibilidades mayores para generar la ansiada nueva institucionalidad.

Adicionalmente, en esta fase del proceso, se ha evidenciado con absoluta claridad un particular fenómeno de hipertrofia gubernamental, anclada, desde luego, en lo que el sistema de gobierno interpreta del descontento y expectativas mayoritarias de los ciudadanos. Resulta prematuro, en esta muy compleja y confusa transición sociopolítica, avizorar si los

5 En los derrocamientos de Bucaram (1997), Mahuad (2000), Gutiérrez (2005), aunque con características y matices diferenciados, el objetivo que la protesta fue decantando en su evolución se concentró en expulsar al presidente del gobierno. Esto, varía en el mandato de Alfredo Palacio y se altera sustancialmente en la presidencia de Correa, por razones de dominio público. 
costos del desmontaje institucional podrán revertir luego en un modelo institucional que permita superar las enormes desigualdades e inequidades vigentes en el Ecuador.

Las borrosas fronteras de la configuración del sistema político determinan también que el conflicto social esté siempre cargado o sobrecargado de expectativas políticas de diversa índole. O de modo inverso, las reivindicaciones de cambio social, lejos de plantearse y resolverse como tales mediante la intervención institucionalizada del sistema político, se politizan prematuramente -antes de ingresar en él y sin que existan las condiciones para una real participación en los ámbitos decisionalestransitando abruptamente de la figura de conflicto social hacia la de conflicto político, privilegiando así la forma de protesta.

Todo ello, como producto de problemas estructurales del sistema político en su conjunto, así como del mismo sistema social que, al no poder ser superados han generado ám- bitos de complejidad difícilmente procesables con lo cual la protesta ha ido tomando la forma de rebelión o revuelta ${ }^{6}$ que, en el caso ecuatoriano, sitúa a Quito como espacio central de la movilización.

Según lo anterior, en el Ecuador difícilmente puede establecerse con claridad y precisión suficientes los límites entre el conflicto social y su conversión hacia la forma protesta ${ }^{7}$. $Y$ esta dificultad se expresa de forma evidente en las trayectorias de la acción colectiva de diversos actores y movimientos que pueden fácilmente moverse en los escenarios de la acción social cuanto en las arenas políticas. En tal medida, las demandas sociales que requieren reformas sociales pueden adquirir, de un momento a otro, el carácter de exigencias de reformas políticas.

En este sentido, y en términos de política práctica y de eficacia política, la protesta social en el Ecuador contemporáneo generalmente ha sido, aunque no corresponda a su ámbito, una acción de orden político por una

6 La revuelta o rebelión, en el marco de las luchas sociales, se la entiende como un movimiento colectivo portador de reclamos y demandas cuya forma ideológica general se muestra difusa y, generalmente, poco elaborada políticamente, caracterizándose, además, por sus rasgos espontaneistas: “...no propugna una subversión total del orden constituido, sino un retorno a los principios originarios que regulaban las relaciones autoridades políticas-ciudadanos [...] La rebelión puede por tanto ser aplacada tanto con la sustitución de algunas personalidades políticas como por medio de concesiones económicas" Se limita, además, a un área geográfica circunscrita. Cfr. Norberto Bobbio, op. cit., p. 1412.

7 J. Sánchez Parga, op. cit. 


\section{En el Ecuador difícilmente puede establecerse con claridad y precisión suficientes los límites entre el conflicto social y su conversión hacia la forma protesta.}

serie de razones que van desde la escasa capacidad de diferenciación entre el ámbito de acción colectiva de los ciudadanos y el ámbito de responsabilidades del sistema político hasta el ambiguo papel de los partidos políticos y movimientos sociales, mimetizados en uno y otro ámbito.

En rigor, los conflictos sociales, como expresión y resultado de un sistema social profundamente desigual y de un sistema político vorazmente corporativo, han tendido a politizarse prematuramente sin que, como se ha dicho ya, medien los canales e instancias previstas por el funcionamiento y organicidad democráticos, de lo cual, en modo alguno, puede responsabilizarse únicamente a los grupos organizados de la sociedad y a las acciones más o menos espontáneas que diversos segmentos poblacionales han llevado a cabo.

Bajo estas consideraciones, se propone el tratamiento de las rebeliones quiteñas como un producto sociopolítico específico, enmarcado en la dinámica de un conflicto social crecientemente desigual, en el que los intereses de los grupos sociales dominantes se transforman directamente en indicadores de política, obligando con ello a que los actores y grupos sociales con menor poder acumulado opten por la vía de la protesta.

En suma, los intereses dominantes expresados en el sistema de representación y en la misma esfera gubernamental ${ }^{8}$ determinan una incapacidad estructural e institucional de los actores que deberían "expresar los conflictos políticos de manera productiva, canalizándolos en estructuras apropiadas y sin que exploten inesperadamente por no tener previstas las salidas".

1980-2006, por delimitar en un marco más acotado el fenómeno de la protesta y por no contar aún con varias de las definiciones estratégicas que consoliden la política gubernamental en la presidencia de Rafael Correa. Con todo, y por razones que pueden ser perfectamente comprensibles en el contexto sociopolítico ecuatoriano, existe la imposibilidad real, de todas las instancias y actores, de un procesamiento democrático del conflicto social y del conflicto político. 
Lo señalado podría constituir la matriz explicativa general desde la cual se despliega una multiplicidad de motivos y formas que, por una parte, dan lugar a la protesta $y$, por otra, la caracterizan. En suma, se advierte el carácter persistente de la protesta bajo diversas y cambiantes formas determinadas por sus causas, actores, espacios y estrategias.

\section{Trayectorias de la protesta y rebeliones quiteñas}

Al hablar de las trayectorias de la protesta hacemos referencia a la inevitable situación y condición en la que se encuadra la protesta, como forma de expresión de las demandas sociales de justicia e igualdad $y$, como principal expresión de descontento popular frente a la imposibilidad de que el funcionamiento del sistema político $y$, especialmente de los grupos dominantes de la sociedad doten de institucionalidad al conflicto social.

La ausencia e inobservancia generalizada de reglas del conflicto y las pretensiones de imposición unilate- ral de las mismas han terminado por agotar el campo de la producción del conflicto social, como espacio privilegiado y fundacional de la democracia, para dar lugar a variantes de contradicción social portadoras de violencias políticas, una de cuyas expresiones más importantes son las protestas de rebelión actuales. Las rebeliones quiteñas, se inscriben en este marco analítico.

En otras palabras, la creciente imposibilidad estructural de (re) generar procesos viables para la consecución de mayor igualdad social, expresados, sobre todo, en la incapacidad redistributiva del Estado, una permanente y agudizada crisis de representación, así como las crecientes restricciones en el ámbito de la acción gubernativa entre el gobierno de Hurtado y el de Palacio hasta la hipertrofia gubernamental del régimen de Correa, sus consecuentes efectos en la política pública y en la política social, han determinado que los espacios de contestación social y ciudadana adopten la protesta de rebelión, antes que insurrecional ${ }^{12}$, co-

10 Definida la insurrección como "movimiento generalizado de un núcleo de individuos contra el poder dominante que, ordinariamente se puede identificar con el gobierno..." difícilmente a las protestas actuales podría atribuírseles, directamente y obviando todo un debate sobre el "horizonte revolucionario" de la protesta, un carácter insurreccional, puesto que la insurrección, en rigor, se enmarca explícitamente en un proceso revolucionario más amplio, como uno de sus atributos básicos. Cfr. N. Bobbio, op. cit., p. 813. 
mo el principal espacio de la puesta en acto de las contradicciones sociales $y$, como el instrumento que mayores eficacias reporta en la confrontación con el gobierno y con el congreso, aunque sus alcances sólo puedan dimensionarse bajo la mirada de un proceso. En tal sentido, la protesta responde a las propias deficiencias del sistema político y expresa, además, la escasa capacidad de la sociedad para concretar acuerdos mínimos y, en alguna medida, perdurables.

Pero es el conjunto de precariedades sociales y políticas las que, cabalmente, parecen activar y fortalecer la protesta y hacer de ésta una rebelión. En ausencia de mecanismos institucionales consolidados para el procesamiento del conflicto social y del conflicto político, la protesta de rebelión emerge con mayor intensidad, tal como ha podido observarse, en períodos recientes, en varios países de América Latina.

Lo que sí parece necesario puntualizar es que no son las protestas en sí mismas, ni sus actores más visibles los que han producido el derrocamiento y destituciones presidenciales, y más recientemente la desti- tución de diputados, por lo menos en el caso ecuatoriano ${ }^{11}$. Existe un conjunto heterogéneo de fuerzas e intereses que, con distinto nivel de persistencia y consistencia, ha sido partícipe de las revueltas suscitadas en Quito.

De tal forma que las protestas y rebeliones condensan un cúmulo de fuerzas contenidas que se liberan bajo formas y estrategias directamente dependientes del capital económico, social, cultural y político de los grupos e, incluso, "individuos no organizados” que participen. De allí que resulta particularmente importante el análisis longitudinal sobre la incidencia de la participación de los sectores medios en las revueltas quiteñas, relacionando el período histórico específico con el carácter de las medidas, sobre todo económicas, adoptadas por los sucesivos gobiernos y con la conducta política de bloqueo y pugna persistente entre los poderes del Estado.

Pero, sobre todo, la protesta de rebelión en el momento actual expresa, más allá de los valores y discursividades que se enarbolen, la reacción social de las clases y sectores medios a la profunda crisis en la que 
se halla sumergido el sistema político y la misma democracia, que al haber sido supeditados a las imposiciones del mercado e intereses corporativistas de reducidos segmentos de la sociedad se vuelven incapaces de garantizar el bien común como principal precepto del estado democrático moderno. Hecho que, hacia mediados de los años noventa, ha empezado a afectar con mayor intensidad a los sectores medios de la sociedad.

En la revisión histórica de las rebeliones quiteñas y transformaciones de la protesta, en general, resulta sumamente importante el análisis de la composición de las fuerzas de contestación y su acumulado de poder específico. Como se verá más adelante, los efectos de las protestas y sediciones de mayor alcance en el Ecuador y América Latina, además de responder a la incapacidad estructural y deformaciones institucionales del sistema político, condensan de manera fehaciente un aspecto relativamente novedoso que es la cada vez más notoria frustración de expectativas de clases medias y de ciertos sectores sociales relativamente acomodados.

\section{La protesta y el camino de retorno a la democracia: de la ampliación diversificada de los sectores medios a la reducción creciente de movilidad social}

A partir de la década del setenta, la protesta social en el Ecuador y, específicamente en Quito, capital de la República y epicentro de la dinámica política nacional, ha mostrado importantes variaciones tanto en sus formas como en el carácter de sus demandas $y$, en el caso ecuatoriano de forma similar al resto de América Latina, se ha instalado en el campo del conflicto político ${ }^{12}$ debido, sobre todo, a las decisivas transformaciones de la acción y políticas gubernamentales, especialmente, desde los años ochenta.

En este sentido, y como rasgos relevantes, cabe referirse a la ya mencionada opacidad institucional del sistema político, a la agudización tendencial de la crisis de representación, a la errática acción gubernamental y a una marcada racionalidad institucional corrupta. Todo lo cual ha nutrido, hasta la presente fecha, un incontestable proceso de deslegitimación del sistema democrático 
como efecto general del conjunto de factores políticos enunciados.

Si bien la protesta es indisociable, y factor constitutivo de las luchas sociales, en el Ecuador parece necesaria aquella distinción entre conflicto social y ciclo político de la protesta ${ }^{13}$, ya que permitiría entender las transformaciones y continuidades de la lucha social en el último período democrático hasta las revueltas actuales que, en el caso ecuatoriano, desencadenaron el derrocamiento de Lucio Gutiérrez en 2005 y contribuyeron en cierta medida a la destitución de 57 diputados, luego de la decisión tomada por el Tribunal Supremo Electoral.

Se plantea, por tanto, que las luchas sociales en sus distintas variantes remiten y se explican por el carácter sociopolítico del estado ecuatoriano en cada una de las décadas enmarcadas en el último período democrático. Y, por otro lado, que las luchas políticas responden a los con- flictos generados y desatados desde el sistema político más que desde la misma sociedad.

Es decir, que el tránsito de un cada vez más desregulado, y por consiguiente imposibilitado, conflicto social-democrático- hacia formas más intensas de protestas de rebelión se explica, principalmente, por la políticamente deficitaria acción gubernamental ${ }^{14}$, el inevitable deterioro del sistema de representación y la ineficiencia estructural de la institucionalidad pública a lo que habría que agregar, como primer efecto de esta descomposición sistémica, la desintegración acelerada del tejido social en su conjunto ${ }^{15}$.

Este señalamiento es de fundamental importancia en la explicación de los alcances de la protesta de rebelión en el momento actual. El conjunto de características descritas parece confirmar, como se ha señalado ya, que no es desde la sociedad que se genera el conflicto fundamental,

13 Cfr. J. Sánchez-Parga, op. cit.

14 Atrofia e hipertrofia gubernamental se presentan, en distinto grado y según las particularidades del régimen político de cada país, como las dos caras, indisociables, de la acción gubernativa; atrofia gubernamental determinada por el peso de las indicaciones e imposiciones políticas externas, lo cual restringe cada vez más el "margen de maniobra" de los gobiernos, e hipertrofia gubernamental expresada en la cooptación de todos los poderes y funciones del Estado por parte del gobierno. La coyuntura actual haría pensar que se impone esta segunda característica como condición necesaria para la recomposición y reestructuración del sistema político y, según, varias perspectivas del modelo societal.

15 Cfr. Fernando Bustamante, La política y la picaresca: reflexiones sobre el no tan nuevo orden de la "sociedad patriótica", en Ecuador Debate n. 61, Quito, abril 2004. 
puesto que no existen condiciones democráticas para aquello, sino, es desde el sistema político que se provocan un conjunto de reacciones sociales muchas veces impredecibles.

Las rebeliones quiteñas han seguido esta trayectoria; desde las luchas reivindicativas, generalmente gremiales, sindicales o estudiantiles contra diversos estamentos de la esfera gubernamental -incluido el propio Presidente- hasta las luchas de asociación masiva y múltiple contra el sistema político en su conjunto, aunque con intensidades diferenciadas respecto de uno u otro susbsistema.

En la misma dirección, es igualmente importante revaluar el uso conceptual del término conflicto, lo cual supone su tratamiento sociológico que lo ubica como la fuente de las libertades y la democracia ${ }^{16}$. Y, de modo particular, el conflicto social que, como sabemos, condensa los diversos y específicos intereses y tensiones de los distintos grupos sociales y configura un complejo espectro de consensos y disensos que, se supone, serán finalmente procesados y sancionados por el sistema político. Hecho que, en última instancia y en la dimensión teórica, representa el perfeccionamiento del sistema y régimen democráticos.

Durante los años setenta en Ecuador, y pese a la vigencia de un régimen político no democrático y militarizado, podría afirmarse que las movilizaciones de protesta desarrolladas en Quito, en particular la llamada "guerra de los cuatro reales", se inscribían en un clima social caracterizado por tensiones y conflictos sociales más claramente regulados que en las dos décadas siguientes y, sobre todo, en un período de bonanza económica expresada, en las acciones y efectos redistributivos de los ingresos petroleros.

Con otras palabras, el diseño institucional a través de las políticas estatales de los gobiernos militares, especialmente el de Rodríguez Lara, siendo parte de un régimen dictatorial, garantizaba de manera "forzada”, pero más efectiva, que los sucesivos gobiernos democráticos, la presencia de un conflicto social, generalmente latente, que se regulaba y atenuaba no sólo por acción de los dispositivos de gobierno de la particular dictadura militar ecuatoriana, sino por los efectos de una más objetiva

16 "Más que una mera desviación destructiva, el conflicto es un hecho creativo y deviene inevitable en la vida social." Cfr. Stanley Heberle, Sociología, Madrid, 1973. 
participación social, especialmente de las clases medias, en la redistribución de la riqueza nacional.

No se pretende decir con esto, y menos justificar, que un régimen dictatorial de las características que fuere, es preferible o más aceptable que una democracia restringida. Lo que sucede es que en el caso ecuatoriano, por una serie de factores que van desde la composición de clase de las Fuerzas Armadas hasta circunstancias coyunturales de orden político y económico -economía boyante-, por ejemplo la de los años setenta; el régimen democrático reestablecido a partir de 1979 ha carecido de la consistencia necesaria como para garantizar las libertades ciudadanas en un (supuesto) marco de supresión progresiva de las enormes desigualdades sociales.

En todo caso, más allá de esta digresión que, como veremos, contribuye en gran medida a explicar la transformación de la protesta social de los años setenta y ochenta en las protestas de rebelión de los años noventa y, específicamente, a explicar el papel de las protestas y rebeliones quiteñas en el derrocamiento de los ex presidentes Bucaram, Mahuad y Gutiérrez, es la progresiva precarización de las condiciones de vida de cada vez más vastos segmentos poblacionales provocada por los efectos de un conjunto de políticas económicas de corte neoliberal 17 el principal factor de las revueltas suscitadas en Quito, aunque como en el caso de la rebelión forajida, los factores desencadenantes, coyunturales y más visibles se ubiquen en ámbitos distintos al de la política económica.

En efecto, lo que se observó en los hechos que constituyeron la rebelión de los forajidos fue, sobre todo, la defensa de los valores y discurso democráticos, puesto que las drásticas expresiones de la hipertrofia presidencial ${ }^{18}$, en el contexto de la política interna, desencadenaron una problemática que había venido incubándose desde al menos, una década atrás y

17 La bibliografía sobre el tema es abundante. Una perspectiva general a nivel regional se presenta en el documento CEPAL, Informe económico 1982-1999, Diecisiete años de neoliberalismo en América Latina, Santiago. Un análisis estructural centrado en la deuda externa puede verse en Alberto Acosta, La Deuda Externa, Libresa, Quito, 1994. Un análisis introductorio sobre la supeditación funcionalizada de las políticas sociales de infancia a las políticas económicas se presenta en R. Unda, Sociología de la Infancia y Política Social, en Infancia y Adolescencia. Aportes desde la Sociología, Ifejant, Tomo I, Lima, 2003.

18 Cooptación de la CSJ, Tribunal Constitucional,TSE. Hipertrofia expresada también bajo formas de cooptación clientelar de cargos burocráticos en una diversidad de instituciones. Cfr. Franklin Ramírez G., La insurrección de abril no fue sólo una fiesta, Abya-Yala, Quito, 2005. 
cuyos estallidos sobresalientes fueron el derrocamiento de Bucaram (1997) y Mahuad (2000).

Dicha problemática puede definirse como el progresivo desplazamiento y deterioro de las clases medias, consecuencia de la estructural aplicación de políticas neoliberales y de la coyuntural pugna interoligárquica. Lo cual se traduce, sociológicamente, en una creciente frustración de expectativas de amplios sectores de las clases medias que adquirió formas de rebelión gracias a las erráticas o deliberadamente extra-legales acciones gubernamentales de Gutiérrez. Evidentemente, los desplazamientos y deterioro aludidos recubren, antes que a las clases medias, los sectores más empobrecidos de la sociedad y adquieren diversas manifestaciones de exclusión y violencias.

Lo vivido en abril de 2005, en términos de rebeliones quiteñas, encuentra su punto de enlace con el proceso, brevemente descrito líneas atrás, de expansión y diversificación de las clases medias de los años setenta y su progresivo -inevitable, incluso- desplazamiento y deterioro.

El desplazamiento progresivo de los ámbitos político y económico de los sectores medios se expresa en una creciente desconfianza hacia el sistema político y régimen democrático, y en un desplazamiento real de la esfera de la participación de la riqueza nacional a través de variantes como la cada vez más constreñida movilidad social, incertidumbre e inestabilidad laborales, desempleo y subempleo, migración forzada.

$$
\begin{aligned}
& \text { Los desplazamientos } \\
& \text { y deterioro aludido } \\
& \text { recubren, antes que } \\
& \text { a las clases medias, } \\
& \text { los sectores más } \\
& \text { empobrecidos de la } \\
& \text { sociedad y adquieren } \\
& \text { diversas manifestaciones } \\
& \text { de exclusión y violencias. }
\end{aligned}
$$

Si bien las clases medias no siempre han protagonizado las rebeliones quiteñas, puede afirmarse con certeza que aquello sí sucedió en la rebelión de abril de $2005^{19}$. Pero atribuir únicamente a las clases medias toda la iniciativa y responsabilidad de la revuelta forajida sería inexacto. Tan- 
to desde las capas dominantes de la sociedad como desde las clases bajas se ejercieron acciones que confluyeron en la destitución de Gutiérrez.

$\mathrm{Si}$, como acertadamente señala Ramírez, el "problemático y ambiguo" concepto de clase media impide afirmar categóricamente que la revuelta forajida sea atribuible exclusivamente a la clase media, no es menos cierto que ella, en tanto sustrato sociocultural de líderes y organizaciones populares, castrenses, institucionales, gremiales, sindicales, estudiantiles, etc., atraviesa mayoritariamente los espacios de contestación latente o manifiesta de la sociedad ecuatoriana. Principalmente, desde la década del setenta.

En tal sentido, creemos que el análisis de las rebeliones quiteñas, a partir de 1978 con la "Guerra de los Cuatro Reales", jamás podrá prescindir del análisis del papel de los sectores medios. Pero aquello sólo será posible decantar si el análisis trasciende el limitado marco temporal de cada movilización o revuelta. Únicamente comprendiendo cuál ha sido la evolución del conflicto social y político, así como sus conversiones e hibridaciones, especialmente, a partir del último período democrático, podrá explicarse cómo las clases/sectores medios adquieren, de modo progresivo, una presencia protagóni- ca en las protestas de rebelión antigubernamental y antiinstitucional de la política establecida.

Por ello, y volviendo a una emblemática movilización de protesta enmarcada en un período de predominio de la conflictividad social más que de conflictividad política, como fue la "Guerra de los Cuatro Reales", en términos de consistencia de actores y estrategias de la protesta, cabe hipotizar sobre el tránsito de una presencia restringida hacia una de carácter decisivo de las clases medias en la censura frente a una también cada vez más rígida aplicación de políticas neoliberales que las afectan, como factor persistente del creciente descontento, y frente al desmoronamiento de símbolos, valores y discursos representativos de la institucionalidad democrática liberal.

La persistencia del factor estructural -políticas neoliberales- y que podría, incluso, percibirse como "subyacente", afecta obviamente a amplios sectores que van más allá de las clases medias. Ha estado presente, desde la década de los ochenta, con la aplicación de las políticas de ajuste estructural y ha recubierto y permeado el orden económico y político de la sociedad sin que su difuminación se presente, necesariamente, como una afrenta a la democracia. Por lo tanto, sus efectos de progresiva exclusión de 
vastos segmentos y capas poblacionales deben considerarse en términos de su persistencia e irradiación.

En tal medida, no es sino hasta entrados los años noventa cuando los sectores medios se ven cada vez más expuestos, sobre todo, a las contingencias derivadas de las transformaciones del mercado de trabajo, lo cual desencadenará una espiral creciente de problemas sociales con el consiguiente reacomodo societal marcado por exclusiones más permanentes de los sectores más empobrecidos. Lo que no dejará de incidir en una creciente y más "visibilizada" presencia de las clases medias en las movilizaciones de protesta.

Aquello que en los años setenta generaba espacios de convergencia de la protesta social bajo la consigna de la lucha antiimperialista -quizás por la imposibilidad real de enfrentar un régimen dictatorial doméstico y, sobre todo, porque las "condiciones objetivas" de la reproducción social estaban más o menos satisfechas en la mayor parte de la sociedad- en los años ochenta, en cierto modo, declina o se reorienta por el espejismo de autonomía e independencia creado por la vuelta a la democracia que, como contraparte, acarreaba también la aplicación gradual de políticas de ajuste estructural de corte fiscal como eje de las acciones gubernamentales.

En gran medida, durante las dictaduras militares de los años setenta, la esfera gubernamental, por diversas razones estaba bastante encapsulada, acorazada incluso, y objetivamente tenía la suficiente capacidad y margen de maniobra para redistribuir, sobre todo, en la recientemente diversificada clase media, la riqueza generada por las exportaciones petroleras ${ }^{20}$. El conflicto político, en un régimen castrense, se resolvía bajo los cánones de regulación militar sin que la "Sociedad Civil" pueda intervenir, tal como sucedió, por ejemplo, en la sublevación contra el gobierno de Rodríguez Lara, encabezada por el general Raúl González Alvear en 1975.

De tal forma que, movilizaciones como la "Guerra de los Cuatro Reales" de abril de 1978, cuya motivación central fue la protesta contra el alza de los pasajes, comporta, fundamentalmente, una reivindicación de carácter social más que político. Aún cuando haya estado muy presente la consigna de la lucha antiimperialista, mediante los temporalmente cesados núcleos y partidos políticos de izquierda $y$, adi- 
cionalmente, de que se haya realizado en Quito, centro simbólico de las conspiraciones políticas del país.

Es importante anotar aquí la fuerte presencia del movimiento obrero cuya traducción más precisa serían las fuerzas sindicales como eje de la movilización. Pero asimismo, es importante anotar el carácter movilizatorio -no necesariamente de concentración y ocupación callejera- generalizado de amplias franjas populares desvinculadas de organizaciones sociales y políticas, así como tampoco fue una cuestión menor la presencia de diversos segmentos generacionales jóvenes que usualmente habían permanecido al margen de las anteriores y escasas movilizaciones.

Con todas las distancias del caso, las protestas de abril de 1978 marcan un hito en cuanto al carácter cooperativo de la movilización y con respecto a la presencia de jóvenes no vinculados a organizaciones y movimientos políticos. Aunque la existencia de registros y análisis sobre esta movilización sea mínima, emerge claramente, sobre todo desde la in- formación testimonial; la presencia de jóvenes "no organizados" así como las formas y mecanismos de ayuda entre vecinos y ciudadanos interesados en protestar por el alza de pasajes, puesto que aquello afectaba de forma mucho más amplia e intensa a la ya urbanizada sociedad quiteña ${ }^{21}$. A todo ello es importante agregar que la sociedad ecuatoriana y Quito, de modo particular, se aprestaba o vivía ya los albores de una transición conducente al restablecimiento de la democracia, hecho que avivaba posturas y discursos movilizatorios.

Por lo tanto, la presencia de ciudadanos no vinculados a organizaciones; así como la incorporación de "repertorios de la cotidianidad" (Ramírez, 2005), en tanto categoría sociológica, es una dimensión no tan nueva ni novedosa con relación a las protestas de abril de 2005. Quizás, las repetitivas estrategias de las movilizaciones y protestas de los años ochenta y noventa sean el factor que induzca a percibir las innovaciones movilizatorias de 2005 al margen de las continuidades de la protesta.

21 Al respecto resulta muy ilustrativa la apreciación de un contestatario de siempre como Jaime Guevara, músico popular con mayores apegos al rock, quien en una entrevista a propósito de una investigación sobre el movimiento rockero en Quito, indica que en la "Guerra de los Cuatro Reales" "....como nunca antes se vio en las calles a jóvenes de colegios particulares mezclados con gente de la FEUE, incluso a peladas (cursiva nuestra) de esos colegios quemando llantas, lanzando piedras y sonrisas, fue muy chévere, pero también hubo mucha represión", cfr. René Unda, Identidad y Movimientos Sociales: El proceso de introducción del rock en Quito. PUCE, tesis de Licenciatura, Quito, 1996. 
Como un rasgo que persiste de la protesta y del conflicto social, bajo la forma de protesta de rebelión, la "Guerra de los Cuatro Reales" orientó el grueso de sus cuestionamientos, más o menos violentos ${ }^{22}$, hacia el gobierno y, de modo particular, hacia el triunvirato militar.

El reclamo contra el gobierno, como rasgo constante de la protesta, revela la dimensión (hiper) personalizada de la estructura gubernamental o del sistema de gobierno, característica sobresaliente del sistema político ecuatoriano, hecho quizá explicable por el peso de la tradición familiarista-patriarcal y muy poco institucional de la vida política. A la larga, veremos que esta observación permite comprender el actual funcionamiento y caracterización de la política nacional como estructuras mafiosas ${ }^{23}$.

Como contraparte e, incluso forma complementaria de la estructura y funcionamiento políticos en el país, conviene notar la débil consistencia del tejido social, por lo menos con referencia al sistema político. Las graves y enormes asimetrías socioeconómicas, las distancias y confrontación de orden sociocultural y el extrañamien- to mutuo entre Estado y sociedad han cimentado un campo de culturas políticas caracterizado por la simplificación intelectiva y procedimental de los procesos sociopolíticos.

Esta observación, expresada de muy diversas formas en los estudios políticos sobre el Ecuador, ha sido también la que ha enmarcado y, en gran medida, ha determinado la trayectoria y tendencias de la protesta, así como también ha condicionado el relativo protagonismo de actores, espacios y estrategias.

Por ello, un análisis del ciclo actual de la protesta supone, necesariamente, no sólo una revisión historiográfica de los hechos sino, sobre todo, el despliegue de una sociología histórica. Sólo de esa manera podremos comprender la naturaleza del cambio y transformaciones del papel y protagonismo de los actores y, específicamente, de las clases medias quiteñas.

Cerrando esta aproximación a las movilizaciones de abril de 1978, resulta pertinente remarcar algunos de sus rasgos particulares que permitirán entender las continuidades y rupturas de la protesta:

Entendida la violencia bajo sus posibles variantes: violencia física, material o moral. Cfr. N., Bobbio, ob. cit., pp. 1627-1628.

23 Cfr. F. Bustamante, op. cit., Ver también Julio Echeverría, La Democracia Bloqueada. Teoría y crisis del sistema político ecuatoriano, Letras, Quito, 1997. 
- Identificación del gobierno como el principal "enemigo" a derrotar.

- Protagonismo protestatario de organizaciones y movimientos políticos.

- Demanda reivindicativa de carácter social (contra el alza del pasaje).

- Presencia-restringida pero inédita- de segmentos poblacionales "no organizados".

- Emergencia de formas de acción colectiva de carácter cooperativo e incorporando a la protesta estrategias, (convergencia barrial en espacios previamente acordados, humor) e imperceptiblemente, "repertorios de la cotidianidad" (ayudas diversas de vecinos - agua, llantas, cigarrillos- colecta -"vaca"para gasolina, cánticos introducidos por expulsados, exiliados $y$ perseguidos por las dictaduras del cono sur del continente, con apropiaciones y mixturas quiteñas).

\section{Ajuste estructural y retrocesos institucionales en los años ochenta. Escisión y desgaste de la protesta frente a los-inadvertidos- procesos económicos de alcance global.}

Desde una perspectiva más estructural, cada fase de la protesta, a partir de los años ochenta, responde, de manera más directa, a los efectos de los condicionamientos externos, en los cuales deberíamos también leer las transformaciones de las contradicciones y desgaste democráticos que se harán más visibles e incontrastables hacia finales de aquella década. El retorno a la democracia supone también una tendencia hacia la desregulación -indetenible hasta ahora- de los procedimientos estatales y nacionales, instaurados en la década del setenta, mediante la cual adquieren mayor peso las indicaciones e intervenciones externas en el marco de la mundialización creciente de las relaciones sociales ${ }^{24}$.

Desde el inicio de esta década se dejan sentir ya los efectos del peso de la deuda externa que se había incrementado en, aproximadamente, diez veces más desde el inicio del periplo petrolero de los años setenta. El rediseño institucional del Estado fijó sus soportes de funcionamiento en la apuesta al crecimiento económico basado en una creciente pero radical austeridad fiscal anclada, sobre todo, en el congelamiento y recorte del gasto social, concretando con ello las primeras señales inequívocas de un irreversible proceso de incapacidad 
redistributiva del Estado con lo cual el escenario de la crisis económica queda, en su relación con lo social, claramente delineado.

En otras palabras, las medidas adoptadas en el contexto del "ajuste estructural" institucionalizan la subordinación y supeditación de lo social a lo económico, cuestión que además de separar estas dimensiones constitutivas y complementarias del Estado moderno orientado hacia la búsqueda y consecución del bienestar ciudadano, instala y promueve una agresiva arremetida de lógicas y procedimentalidades de privatización creciente de lo público.

El peso decisivo de un proceso de integración -gradual pero inadecuado- internacional bajo la égida neoliberal determina, por otro lado, una acumulación progresiva de capital decisional en el ejecutivo, con lo cual el sistema de representación en su conjunto aparece neutralizado o, a la inversa, tiende a convertirse en la principal dificultad para la llamada gobernabilidad democrática cuando sistemáticamente bloquea las decisiones presidenciales que, de modo real o no, intentan satisfacer las demandas ciudadanas.

Más allá de que esta producción de conflicto político, relativamente novedosa para la época, reste perspectivas de consolidación efectiva de la democracia, lo que aquí corresponde abordar es el problema del traslape de la conflictividad política desde el sistema político hacia la sociedad en su conjunto. Es decir, de la configuración de actores que habían devenido en movimientos sociales hacia sus haceres como actores políticos.

\section{Es la crisis de representación, en sus distintas fases y en sus complejas articulaciones con los componentes del sistema político, lo que nutre la presencia y acción de lo movimientos sociales.}

Es la crisis de representación, en sus distintas fases y en sus complejas articulaciones con los componentes del sistema político, lo que nutre la presencia y acción de los movimientos sociales que a estas alturas (lapso 1981-1984) han desarrollado un rápido proceso de constitución en las dimensiones física e identitaria, hecho que se expresa en una cadena de movilizaciones que terminan por in- 
tensificar la diversificación del movimiento social en detrimento de su consistencia hacia fines de los ochenta y, sobre todo, de las organizaciones matrices que las dieron origen (FUT, CEOLS, UNE, entre las principales).

Así, las movilizaciones y protestas de 1982, exigiendo reformas a las medidas tomadas por el gobierno de Hurtado, y que tuvieron una especial significación en términos de una maniquea confrontación regional Guayaquil-Quito, se inscriben ya en el marco histórico de las reformas de ajuste estructural que inducen a una más intensa y abierta politicidad de la protesta. En términos de conflicto social, el escenario democrático, excepto en el período del gobierno de Febres Cordero, aún garantizaba la posibilidad de una participación social que, aunque sujeta a constreñimientos y no mayormente demandada, se expresa en márgenes de redistribución, siempre decreciente, de la riqueza.

Ello explica el que la mayor parte de los movimientos sociales se hayan constituido y consolidado en esta década $^{25}$. El conflicto, como aspecto constitutivo de la democracia, permite también la constitución del mo- vimiento social, hecho que si bien expresa la vigencia del régimen democrático como espacio natural de los movimientos sociales, encubre también las reales y específicas expectativas del movimiento social, excepto el indígena de aquel momento, cuyo discurso se orientaba claramente hacia la transformación societal por la vía de las reformas sociales y jurídicas de integración como condición previa de la reforma política en un momento en el que el movimiento indígena se iba dotando de mayor politicidad y, a la par, iba constituyendo su brazo político.

En ese sentido, puede evidenciarse durante los ochenta, la relativa facilidad con la que el movimiento social lograba politizarse o más exactamente volverse un movimiento político no necesariamente bajo la forma de partido. Y de allí que el carácter de la protesta haya tenido siempre un fuerte y gravitante sustrato político, lo cual llevaría a concluir, provisionalmente, que la relativa ausencia de luchas sociales con reivindicaciones estrictamente sociales responde al enorme distanciamiento entre clases y sectores sociales, hecho que impidió su relaciona- 
miento vía conflicto social y que lo trasladó directamente al ámbito de las arenas políticas.

En gran medida, el retorno a la democracia evidenció con mayor crudeza que en períodos anteriores, aquella verdad de que los intereses corporativos han estado siempre (auto) representados en el sistema político ecuatoriano ${ }^{26}$, contribuyendo con ello no sólo al erosionamiento progresivo y fatal del sistema político, sino también a la inevitable deslegitimación del régimen democrático y sus instituciones.

Con distintos y hasta muy diferenciados matices en sus políticas económicas, los tres gobiernos que transcurrieron entre 1979-1992 (Roldós-Hurtado, Febres Cordero, Borja) no sólo que no pudieron revertir la crisis, fundamentalmente económica, sino que contribuyeron al desmontaje institucional del Estado por diversas vías, situación que se agravaría con las reformas impulsadas en el gobierno de Durán Ballén.

Este resultado general determina la profundización de la brecha entre el Estado y actores sociales que hacia finales de la década de los ochenta ha producido un variado espectro de movimientos en cuya dinámica se irá incubando el sustrato de la protesta de rebelión, consistente en el tránsito de la oposición a la negación de la acción gubernamental (derrocamiento de Bucaram 1997 y Mahuad 2000) y, posteriormente, negación del sistema político en su conjunto (derrocamiento de Gutiérrez 2005 y "que se vayan todos"). Sin que lo dicho signifique atribuir exclusivamente a la protesta de rebelión la capacidad y responsabilidad de los derrocamientos mencionados 27 .

\section{Los años noventa: una radicalidad de diferente signo}

Con la mundialización creciente de las relaciones sociales, el conflicto social y político se desarrolla en un ciclo claramente dominado por las políticas neoliberales de alcance global, en las que la acción gubernativa intensifica el curso delineado en la década anterior, pero, reduciendo significativamente sus capacidades y competencias decisionales frente a los imperativos de agendas e intereses transnacionales.

A la vez, la reducción del margen de maniobra y conducción política 
de los gobiernos, trae aparejada la implementación de las indicaciones de las fuerzas económico-financieras, sobre todo, globales, mediante los organismos multilaterales, que traducidas en los programas de "saneamiento" fiscal, endeudamiento externo, serias limitaciones a la soberanía nacional y establecimiento de "agendas de riesgo" (Plan Colombia, dolarización, ALCA, TLC) los convierten en gobiernos calamitosos, extremadamente vulnerables y proclives a pendulaciones inauditas que, inevitablemente, los fragilizan ante las presiones exógenas y ante las fuerzas sociales internas.

Se restringe, en suma, la acción gubernamental28 de los gobiernos $\mathrm{y}$, la protesta toma también un nuevo giro: se radicaliza, adquiere un paradójico carácter de intermitencia permanente $y$, a diferencia de las décadas precedentes, adquiere efectos de rebelión que confluyen, generalmente, en coaliciones de dinámicas e intereses en los que pueden incluirse, de modo más o menos predecible, el derrocamiento de presidentes. Cuestión que se generaliza en el ámbito latinoamericano ${ }^{29}$ y que, más allá del peso e importancia de las movilizaciones de protesta, conduciría a repensar el real peso de las fuerzas globales del mercado que hoy imponen agendas incluso a los gobiernos y bloques económicos más poderosos del planeta.

En efecto, una línea de hipótesis sobre las nuevas formas de protesta se configura con mayor fuerza en la actualidad por efectos de la radicalización de las políticas globales que han empezado a generar mayores impactos en los sectores incorporados al mercado laboral y a los circuitos institucionales de reproducción social. Las nuevas formas de protesta, en tal medida, contienen un importante acumulado de reservas morales, políticas e ideológicas de sectores sociales procedentes del variado espectro de los sectores medios que parecen haberse reactivado al verse inmersos, inevitablemente, en una dinámica de crisis generalizada.

El resultado, constatado hasta la presente, es enormemente interesante en tanto incremento de la complejidad de la protesta en términos de: a) internacionalización de la protesta; b) incorporación de discursivida-
29 Cfr. Entrevista de Paul Walter a Atilio Borón, El dilema de los movimientos sociales: a organizar la desorganización, en Rebelión, 14 de julio de 2005. 
des - "repertorios"- de dimensiones y actividades de orden distinto al campo político; c) apelación a valores, a imaginarios políticos y democráticos de alto contenido simbólico mixturadas con reivindicaciones y demandas concretas. En este nuevo marco de la protesta, el factor clases-sectores medios y participación de los/as jóvenes podrían constituir las dimensiones a examinarse con mayor detenimiento y exhaustividad.

Considerando los sucesivos derrocamientos presidenciales producidos desde 1997 en el Ecuador, se constata, por una parte, el progresivo y hasta acelerado deterioro del régimen político en cuanto a su consistencia, tanto en términos de consolidación política e institucional como en su tendencia hacia formas autoritarias de acción gubernamental y deslegitimación extrema de la representación política. Dicho en otras palabras, al grado de consolidación institucional de la política debe añadirse el cómo está organizado el poder político -formas presidencialistas o parlamentarias- y el cómo se ejerce dicho poder ${ }^{30}$, para su eficaz funcionamiento como fuentes analíticas fundamentales desde las cuales pue- de explicarse el carácter actual de la protesta, transformada en una protesta de rebelión.

Los factores enunciados tienen directa incidencia en la producción general de políticas públicas, uno de los vínculos más importantes de conexión entre el Estado y la sociedad. Se ha demostrado, durante los gobiernos de Bucaram, Mahuad y Gutiérrez, que al restringirse la capacidad gubernativa y constreñir la tarea gubernamental al exclusivo ejercicio de la administración de políticas privatizadoras y antipopulares, la acción colectiva de la Sociedad Civil tiende a volverse cada vez más reactiva, con la consecuente producción de un tipo más "ilustrado" de protesta, pero no por ello, exento de nuevas formas de violencia focalizada con mayor intensidad en el gobierno y gobernantes.

El derrocamiento de Bucaram, Mahuad y Gutiérrez, con todas sus especificidades y particularidades políticas e ideológicas, así como de contexto socioeconómico, tienen como denominador común y objeto fundamental de análisis el restringido grado de consolidación institucional y margen de maniobra gubernamental inscritos en presiones e indicaciones

30 Cfr. Pedro Medellín Torres, La política de las políticas públicas: propuesta teórica y metodológica para el estudio de las políticas públicas en países de frágil institucionalidad, CEPAL, Santiago, 2004. 
de política inducidas bajo mayores condicionamientos desde los espacios de decisión en el mundo entero.

\section{Puede hablarse también de una crisis diferenciada de autonomía gubernamental y, más ampliamente, del descentramiento de la política -en su sentido y alcance público- como espacio organizador de sociedad.}

Pese a que este proceso de condicionamientos y presiones mundializadas empieza a tener efectos en los primeros años de la década de los ochenta, el sistema político y los diversos actores institucionales y sociales, tardan mucho en advertir sus alcances y efectos, máxime en una economía como la ecuatoriana, imposibilitada e incapacitada para hacer frente a los avatares de la producción y comercio a escala regional y global, como sí han podido enfrentar en años recientes economías como la venezolana y la argentina, por citar un ejemplo.

Por otro lado, buena parte de la intelectualidad oficial, en un ejercicio "bienpensante" de prudencial distanciamiento de las corrientes asociadas a la teoría de la dependencia, han preferido situar en un segundo plano el análisis del peso real de las fuerzas económico-financieras de carácter global, incurriendo al igual que varios sectores del activismo político en errores de apreciación política y sociológica al atribuir exclusivamente a los endebles gobiernos nacionales toda la responsabilidad del descalabro institucional y político agudizado en la década del noventa.

De esas imprecisiones analíticas se desprendieron aquellas explicaciones centradas en el discurso de la traición presidencial que, más que develar el carácter de las relaciones de dominio e imposición "glocales", atribuyen los garrafales desaciertos gubernamentales a la actitud "traicionera y vendepatria" del gobernante de turno, contribuyendo con ello a la mistificación de los problemas políticos y sociales ${ }^{31}$. Exacerbando, por lo demás, de modo hi-

31 Tal como sucedió durante los inconclusos períodos presidenciales de Mahuad y de Gutiérrez. 
perpersonalista un reclamo que debería orientarse, en lo fundamental, hacia la modificación y transformación de estructuras en sus distintos niveles. Al respecto, bastaría constatar cómo los mismos estados, gobiernos y bloques más poderosos del orbe se adecuan y allanan a los imperativos de las fuerzas económicas globales. En tal sentido, puede hablarse también de una crisis diferenciada de autonomía gubernamental y, más ampliamente, del descentramiento de la política -en su sentido y alcance público- como espacio organizador de sociedad ${ }^{32}$.

La hiperpersonalización del conflicto, efecto derivado de la frágil institucionalidad del sistema social y político, se evidenció muy claramente en el derrocamiento de Bucaram en 1997 y, posteriormente, en el de Gutiérrez en 2005. Sólo por mencionar dos de los calificativos más recurrentes y extendidos en las consignas de aquellas rebeliones - "corrupto y traidor"- con toda la carga de veracidad fáctica de dichas consignas; en términos sociológicos y políticos, no hacen más que revelar las concepciones y re- presentaciones más internalizadas en el conjunto de la sociedad; las acciones presidenciales y gubernamentales, según esto, no serían acciones institucionales sino personales. Aunque en el caso de la revuelta forajida, siendo central el efecto de personalización antipresidente, se expandió hacia otras instancias de la esfera gubernamental y del sistema político que mantenían estrecha vinculación con Gutiérrez. Esta observación resulta importante para la comprensión de la agudización de la protesta dirigida contra el Congreso y los diputados, cuestión muy bien percibida por el movimiento ciudadano que candidatizó a Rafael Correa a la presidencia de la República.

Si bien en el derrocamiento de Mahuad, este rasgo antipresidencialista no alcanzó niveles de intensidad comparables a los dos casos mencionados, resultó muy sintomático de la hiperpersonalización del conflicto las acciones de burla y escarnio que los indígenas dirigieron hacia ciudadanos comunes, urbano mestizos, generalmente, oficinistas que circulaban por los entornos del Congreso

32 Cfr. Norbert Lechner, Reflexión acerca del Estado democrático, en Revista Leviatán, n. 49, Madrid, 1992; ver también Guillermo O’Donnell, Otra institucionalización, Revista La Política, Revista de Estudios sobre el Estado y la Sociedad, n. 2 diciembre. Barcelona, segundo semestre de 1996. 
Nacional en la tarde del viernes 21 de enero de $2000^{33}$.

La protesta, con toda la carga de intencionalidad regenerativa del funcionamiento social y político de la que es portadora de varios modos, es parte de todo el proceso de desmontaje de una estructura institucional modernizante diseñada y desigualmente implantada en la década del setenta, en torno del Estado. Y, uno de esos modos o formas en el que la protesta es parte de aquello, radica en la creciente personalización del conflicto en detrimento de su institucionalización, cuyas expresiones más usuales y extendidas hacen referencia a la personalidad corrupta y actitud traidora del presidente de turno y de funcionarios del régimen. Lo cual, como se ha dicho ya, siendo "coherente" en un país que ha institucionalizado el cacicazgo y, actualmente muy deslumbrado por el discurso de los liderazgos, impide que tanto el conflicto social como el conflicto po- lítico en sus diversas formas sean concebidos, explicados y procesados como problemas institucionales.

De tal forma que, la corrupción o el autoritarismo, por ejemplo, se internaliza y maneja en la opinión pública, en el discurso cotidiano e, incluso, en ámbitos académicos, como un mero problema de personalidad atribuible al individuo y, cuando más, al estrecho círculo familiar o profesional que rodea a un presidente o ministro. En realidad, la corrupción o el autoritarismo presuponen, como productos sociales y políticos que son, instituciones $y$, de modo más preciso, un marco institucional que produce corrupción o formas autoritarias y que, simultáneamente, permite corrupción y autoritarismo. Se trata, entonces de una racionalidad -institucional- corrupta que todo lo envuelve y en la que componente fundamental de las mediaciones necesarias para su concreción son los individuos, "sujetos sujetados" de

33 Cfr. Carlos de la Torre, ob. cit., Se han interpretado estas acciones como parte de las estrategias del humor que la población movilizada usa contra todo aquello que represente, simbolice o identifique el poder cuestionado. Creemos, sin embargo que aquello, en el derrocamiento de Mahuad, responde también a la baja o casi nula existencia de vínculos o códigos (contra) identificatorios entre el ex presidente y las amplias bases indígenas, lo cual impidió una crítica personalizada sostenida y elaborada, desde este sector, que no sea aquella referida a las políticas económicas y sus efectos de resguardo al sector bancario-financiero y de empobrecimiento popular, lo que determinó que personas identificadas como "el otro" -similar a Mahuad- sean objeto de burla. Desde sectores medios urbanos, los cuestionamientos poco o nada tuvieron que ver con las formas discursivas utilizadas por Mahuad, aunque persistió la crítica a la personalidad corrupta del presidente. 
una espiral enormemente densa de intereses particulares y privados.

Por ello, las protestas de abril de 2005 en Quito, fueron portadoras de algunos elementos relativamente novedosos respecto de la tensión entre la personalización y la institucionalización del conflicto, hecho explicable, en gran medida, por la amplificada presencia de la "alta Sociedad Civil" 34 uno de cuyos ejes discursivos centrales giró en torno del rediseño institucional del Estado bajo diversas variantes, todas ellas confluyentes en la idea de una muy débilmente delineada democracia participativa.

Durante las movilizaciones de rebelión en Quito, más que la figura presidencial de Gutiérrez, fue la persona del ex presidente el "enemigo" principal. Pero, por otro lado, no deja de ser interesante, en este proceso, el cerrado cuestionamiento y oposición de importantes segmentos de la protesta a las instituciones políticas vigentes y a la política misma. Más allá del registro etnográfico y de la explicación que da cuenta de la incorporación y usos de estrategias relativamente novedosas en la protesta, uno de los aspectos fundamentales para el debate sobre la democracia es el referido a la combinatoria del cuestionamiento radical hacia la persona y hacia las instituciones, aunque esto no pueda generalizarse ni tampoco haya presentado señales claras de persistencia.

Ciertamente, el análisis del radical cuestionamiento e inequívocas expresiones de hastío respecto de las instituciones tienen que encuadrarse en los hechos relevantes que dieron pie a las movilizaciones de abril de 2005. La cooptación, llevada a cabo desde la esfera gubernamental encabezada por Gutiérrez, de instancias y organismos extremadamente importantes y sensibles para la institucionalidad democrática tiene, además, perjudicados inmediatos y directos, si se mira el problema desde la perspectiva de un mayoritario sector de sociedad que no se reconoce en la institucionalidad estatal. Esto, únicamente, para dejar planteadas algunas dudas respecto de la consistencia del reclamo antiinstitucional, cuestión que, por lo demás, no se ha desprendido de un tipo de reclamo y protesta altamente personalista.

Esta observación resulta pertinente en términos de la prospectiva política, trayectorias e, incluso, derivas de la protesta. Porque de seguir primando el carácter personalista en el ejer- 
cicio de contestación o reacción social, soslayando u omitiendo del análisis los alcances glocalizadores de la economía y la política transnacionalizada, la tendencia que parece consolidarse es la de "echar presidentes" o desmontar la institucionalidad y confundir aquello con un supuesto ejercicio de propagación y fortalecimiento de democracia directa.

Por supuesto que a la sociedad, desde una perspectiva democrática radical, le asiste el derecho y las libertades para que, en contextos y circunstancias de persistencia gubernamental autoritaria y erosionamiento institucional de la política, pueda proceder según los acuerdos y consensos mayoritarios en un momento tan complejo como es el de una rebelión. Lo que permanece en cuestión e impregna de una turbia transparencia a muchos de los discursos y actores de las protestas de abril de 2005 es el hecho de que los ejes clave del modelo político institucional y, ni qué hablar del modelo de acumulación económica, queden intocados.

Quizá por ello y para finalizar, el ahora regionalizado reclamo de que "se vayan todos" al adecuarse al caso ecuatoriano, sería uno de los ejemplos más claros con los que puede ilustrarse la muy débil consistencia institucional del tejido social y del sistema político; no se sabe o no exis- te un espesor discursivo, y menos acción colectiva, mediante el cual la sociedad en su conjunto acuerde y determine a dónde es que tienen que irse los políticos, los partidos políticos $\mathrm{y}$ los funcionarios gubernamentales. En este sentido, puede notarse la persistencia de factores atávicos que atraviesan el espectro de clase y etnia y que muy poco han sido considerados en el análisis circulante sobre la protesta.

El "que se vayan todos" adquiere un sentido excluyente cuando quienes lo enuncian son sectores medios hacia arriba, para quienes históricamente les sería imposible despojar de su cultura profunda, una supuesta superioridad y atribuciones sobre la figura del indio mitimae que, expulsado de su comunidad, no es ni representa nada ni a nadie. Hasta ahora, las iniciativas, esfuerzos y discursos políticos por encauzar legalmente los desafueros, arbitrariedades y torpezas del régimen gutierrista han sido muy limitadas, casi inexistentes.

\section{Conclusión. El triunfo de Correa y el redireccionamien- to de la protesta}

De entre las preguntas fundamentales que emergen luego de las movilizaciones de abril de 2005, sur- 
ge aquella referida a cuál ha sido el balance de los efectos de la protesta en términos de configuración de los nuevos o, al menos, renovados escenarios políticos. La pregunta, creemos, no puede limitarse a la postura maniquea y cortoplacista que indaga sobre ganadores y perdedores de las movilizaciones.

Sintetizando lo expuesto, podría pensarse que el ciclo actual de la protesta es un proceso que necesariamente hay que enmarcarlo en las profundas y decisivas transformaciones que, a nivel global, preceden con más de una década a la emergencia de las actuales y generalizadas protestas de rebelión. Esta línea analítica no debería ser examinada como el clásico abordaje estructural y binario expresado en modelos explicativos dependentistas de centros y periferias, de factores externos y factores internos. La fase de la globalización económica atraviesa el mercado global, la política y la cultura. Los centros geográficos y de decisión están descentrados y difuminados, más allá del control de las precarizadas estructuras estatal-nacionales. Sólo bajo estas muy generales consideraciones es que podemos obtener pistas para la comprensión de la emergencia de la protesta anti políticas gubernamentales en sociedades y economías desarrolladas como la alemana (primer trimestre 2005) y la francesa (septiembre-octubre 2005).

En una delimitación más localista, las protestas en la fase de creciente imposición neoliberal han remarcado la importancia simbólica, política y geográfica de Quito, como centro de la protesta $y$, más específicamente, de las nueva formas de protesta. Las rebeliones quiteñas, en gran medida, condensan las demandas, aspiraciones y reclamos nacionales y las dotan del sentido de quiteñidad propuesto en el epígrafe introductorio de este trabajo.

En el imaginario político nacional y regional, a partir de 1997 con la caída de Bucaram, Quito, a través de sus protestas de rebelión, representa un espacio de producción de politicidad que, como "signo de los tiempos”, está asociado a valores civiles y democráticos universalistas (dignidad, soberanía, derechos políticos y sociales) y también a las cada vez más diversificadas reivindicaciones y demandas de las distintas agregaciones societales (jóvenes, ambientalistas, movimientos de derechos humanos, objetores de conciencia, pro libertades sexuales, etc.)

De tal forma que el horizonte de expectativas que emerge en las rebeliones quiteñas está constituido por una muy diversa gama de actores y valores. Hecho que plantea la nece- 
sidad imperiosa de estudios que precisen los límites y posibilidades de una pluralidad que se muestra intermitente, por un lado, y difusa, por otro. El papel de las clases medias, cada vez más golpeadas por la crisis, así como las indagaciones sobre la evolución y carácter de las relaciones entre Estado y sociedad, en la actual fase caracterizada por la presencia, más manifiesta que latente, de la protesta de rebelión, serán con seguridad, algunas de las dimensiones analíticas que alimentarán las agendas académicas e institucionales en el futuro cercano.

\section{Entre los cambios} relevantes de la actual fase de la protesta destaca el fenómeno de alianza con las acciones y decisiones gubernamentales en las que se ha priorizado, bajo distintos mecanismos, la descalificación moral y legal de la mayoría opositora instalada en el Congreso.
De otro lado, el problema siempre presente y que reviste mayor actualidad en la problemática urbana, relativo al de la configuración identitaria de Quito, supone la generación y fortalecimiento de campos de conocimiento que provean explicaciones más afinadas acerca de la quiteñidad en tanto elemento constitutivo de las protestas de rebelión y, recíprocamente, acerca de cómo la identidad quiteña se nutre y atisba nuevas pluralidades en su constitución.

Con la elección de Rafael Correa como Presidente de la República, se ha producido un redireccionamiento de la protesta popular contra la mayoría parlamentaria de oposición al régimen más que contra el poder legislativo. Desde la constitución misma del Movimiento Alianza País se canalizó las expectativas de rechazo al Congreso y a los diputados por parte de un segmento mayoritario de la población, hecho político que sumado a las características y conducta política del líder del partido opositor, PRIAN, pesó fuertemente en el triunfo de Correa.

Entre los cambios relevantes de la actual fase de la protesta destaca el fenómeno de alianza con las acciones y decisiones gubernamentales en las que se ha priorizado, bajo distintos mecanismos, la descalificación moral y legal de la mayoría opositora insta- 
lada en el Congreso. La muestra más evidente de aquello constituye la destitución de los diputados de la mayoría opositora a cargo del Tribunal Supremo Electoral en la que, aunque el gobierno no aparezca como directo ejecutor es el directamente beneficiado en su camino hacia la instalación de la Asamblea Constituyente. La protesta popular ratificó en las calles tal decisión.

De modo simultáneo y como producto de la acumulación de poder en el ejecutivo, la protesta se radicaliza al polarizarse los grupos y sectores que las promueven y que defienden posiciones opuestas. Si bien estas acciones se dieron en los tres derrocamientos presidenciales ocurridos entre 1997 y 2005, el nivel de intensidad de la polarización entre las acciones protestatarias de grupos que querían el derrocamiento y de grupos que apoyaban al presidente ha sido menos intenso del actual en el que se enfrentan quienes rechazan y quienes apoyan a los diputados y a un orden político institucional en franco estado de descomposición.

Bajo las actuales condiciones de crispación política queda todavía un muy largo trecho para confirmar si la protesta, como expresión sociopolítica que pone al descubierto los límites del conflicto democrático regulado, entrará en una fase de debilitamiento o si, por el contrario, se intensificará. Por ahora, la gran apuesta por la que se juega la mayor parte de la población ecuatoriana está cifrada en la Asamblea Constituyente como el espacio fundacional de un nuevo orden social en el que la protesta, y, específicamente, la protesta de rebelión, no sea más que una suerte de recordatorio permanente para quienes han asumido la responsabilidad de la conducción y representación política del Estado. 